\section{DIABETES INSIPIDUS AND INFANTILISM.} To the Editor of THE LANCET.

SIR,-Your annotation on this subject in to-day's issue leads me to draw attention to some recent experiments which testify against the notion that diabetes insipidus and genital atrophy are ever really of pituitary origin. That the genital atrophy of the adiposo-genital syndrome of man does not depend on the posterior pituitary lobe was proved conclusively by the case of Maranon (1911): microscopical examination showed that a hæmorrhagic focus had destroyed the anterior pituitary lobe and had entirely spared the posterior. This case, then, seemed to show that the genital atrophy was brought about by the destruction of the anterior lobe.

But Marrassini and Luciani (1912), after a very extensive series of castration experiments in rabbits and many other mammals, found that macroscopic and microscopic changes in the pituitary were inconstant and insignificant when present. This was confirmed in 1912-13 by Degener and Livingston, who never found pituitary hypertrophy in castrated rabbits. In December, 1913, Iscovesco showed that a special lipoid extracted by him from the anterior pituitary lobe, when injected hypodermically into rabbits for a long period at regular intervals gave no genital changes in either sex on necropsy. In the same month Camus and Roussy, experimenting on dogs, concluded provisionally that polyuria and the genital atrophy of the adiposogenital syndrome are probably not due at all to a lesion of the pituitary, even when, as often happens, a pituitary lesion is unquestionably present, but depend on a neighbouring parapituitary basal lesion which injures centres or paths which are intimately connected physiologically in a way at present unknown with the nutrition of the testes and ovaries. Cushing's unaccountable polyurias after hypophysectomy, then, were due to undiscovered parapituitary lesions caused by the operation; but pituitary operations do not always produce such lesions. In one of Camus and Roussy's dogs a total, or almost total, hypophysectomy was followed by an enormous adiposity with perfect integrity of its testes and sexual functions. Here the adiposity was due to the loss of the posterior pituitary lobe, and the genito-sexual integrity was due to escape of the parapituitary genito-trophic centre and path. It is, of course, true that the posterior pituitary lobe has a diuretic function, and so also (to a slight extent) has Iscovesco's special anterior pituitary lobe lipoid.

We are forced to conclude, therefore, in the present state of our knowledge, that while there are really such conditions as pituitary glycosuria and pituitary adiposity, it is highly probable, if not certain, that pituitary diabetes insipidus and pituitary genital atrophy have no existence in man, rabbit, and dog.-I am, Six, yours faithfully,

London, N.W., Feb. 21st, 1914.

LEONARD J. KIDD.

\section{FRACTURE OF THE EXTERNAL MALLEOLUS. \\ To the Editor of THE LANCET.}

SIR,-As the result of reading Sir John BlandSutton's interesting paper on the treatment of fractures of the external malleolus in THE LANCET of Feb. 7th, I am tempted to ask the following questions: 1. Whether as a routine he removes the external malleolus when fractured? 2. Is there any possibility of a valgus or varus condition of the foot resulting? Under such circumstances would a stiff ankle be better than talipes valgus or varus? 3. Is there any displacement of the peronei tendons, and if so, what means are taken to remedy such displacement?-I am, Sir, yours faithfully,

B. WHITCHURCH HOWELL.

Great Portland-street, W., Feb. 19th, 1914.

\section{GLANDERS IN HUMAN SUBJECTS.}

\author{
To the Editor of THE LANCET.
}

SIR,-May I trespass on rour space and in view of the cases of glander's in human subjects recorded in THE LANCET of Dec. 13th, 1913, p. 1696, by Mr. H. M. M. Woodward and Mr. K. B. Clarke, direct your attention to the very interesting case of chronic glanders in a shoemaker described in the Nederlandsch Tijdschrift voor Geneeskunde, Nor. 22nd, 1913, by Messrs. J. W. van der Valk and H. J. M. Schoo, of Amsterdam?

This is the first case recorded in Dutch medical literature. Full bacteriological examinations were made and excellent plates are giren.

I am, Sir, yours faithfully,

Hubert M. Boshouwers, M.D.

Antofagasta, Chile, Jan. 22nd, 1914.

\section{THE RÔLE OF SYPHILIS IN MENTAL DEFICIENCY AND EPILEPSY. To the Editor of THE LANCET.}

SIR,-In your issue of Feb. 14th you mention the importance of the systematic examination of the mentally deficient both clinically and by the Wassermann reaction, and you refer to the recent pioneer work in England of Dr. K. Fraser and Dr. H. F. Watson.

I should like to point out that in the sixty. seventh report of the Commissioners in Lunacy published in June, 1913, and in our tenth annual report for the year ending March 31st, 1913, I published the results of $m y$ investigations into the incidence of syphilis among 163 mentally deficient patients then resident at this asylum.

I am, Sir, yours faithfully, W. ReEs Thomas,

Senior Assistant Medical Officer and Pathologist. East Sussex County Asylum, Hellingly, Feb. 23rd, 1914.

\section{LONDON : ORGANISATIONS FORMED TO COMBAT THE ACT. \\ To the Editor of THE LANCET.}

SIR,-I am instructed to correct a slight inaccuracy in the account published with this sub-heading in your issue of Feb. 21st.

Definition 6 which reads: "6, National Medical Union, formed in Manchester, and now the federating body for non-panel associations" is not quite correct, inasmuch as the federation is a new body formed at London at a Conference of Non-Panel Associations held on Nor. 29th, 1913.

Definition 6 should therefore read: 6, National Medical Union, formed in Manchester, now a unit of the Federation of Non-Panel Associations under the title of "Manchester District."

This entails the addition of a thirteenth definition: 13, National Medical Union, a federation of non-panel associations formed at London on Nor. 29th, 1913, at a conference of delegates 
representing over 1000 non-panel practitioners in various parts of Scotland and England. At this conference the Manchester society agreed to hand over the title "National Medical Union" to the new federation, itself adopting the designation of the Manchester District of the new body. The federa. tion now known as the National Medical Union is distinct in origin, executive, and policy from the older body of the same name, which together with the Edinburgh Guild and various London nonpanel associations has coöperated in a new establishment. I am, Sir, yours faithfully,

$$
\text { 346, Strand, W.C., Feb. 23rd, 1914. } \begin{gathered}
\text { RobERT CARSWELL, } \\
\text { Hon. Secretary. }
\end{gathered}
$$

\section{THE PUBLIC HEALTH (OPHTHALMIA NEONATORUM) REGULATIONS, 1914. To the Editor of THE LANCET.}

SIR,-These regulations, dated Feb. 5th, 1914, together with a circular letter of the 6th inst., have just been issued by the Local Government Board to local sanitary authorities, extending the compulsory notification of this disease to every sanitary district in England and Wales. They come into force on April 1st, 1914.

The fee of $2 s .6 \pi$. will be paid to medical practitioners for each case arising in their private practice, or 1s. for cases in public institutions, or for Poor-law cases. Midwives will receive $1 s$. for any case, wherever occurring. The actual fees received will be $1 d$. less than stated, as the notifications have to be sent to the medical officer of health by the penny post, if not delivered by hand at the town-hall. If a practitioner and a midwife both notify the same case, are both to receive fees?

The issue of these regulations, besides future regular work, at once provides every medical officer of health with the necessity of finding time to (1) compose and issue a cireular to all medical practitioners, resident or practising in the district of his local sanitary authority; (2) the same to all certified midwives; (3) prepare and issue, guided by the schedule to the regulations, books of notification forms (with counterfoils) for the use of the said midwives; and later on (4) prepare and distribute quarterly fee-account forms to all the aforesaid practitioners and midwives. For this considerable addition to his duties the medical officer of health gets no more remuneration, not even 1s. per case. So the Antitoxin Order, 1910, still retains its distinction as the only Order of the Local Government Board which impressed on local authorities that increased duties should bring increased salary to the poor medical officer of health.

No provision is made in these regulations for the enforcement of any penalties on practitioners or midwives who do not obey them. If the medical officer of health issues books of forms (as instructed) to midwives who practise in his dis. trict but do not reside there, a midwife may receive as many as three or four from different medical officers, causing much confusion, and then might notify a case to the right medical officer of health on the wrong book, or vice versá. It should have been sufficient-as under the Tuberculosis Regulations, 1912-for each medical officer of health to provide books for those midwives residing in his own area. The term "child" is not directly defined, but from article I. (i) of the definitions one presumes that by "child" is meant "an infant less that 21 days old."

No time-limit of 36 hours, as in the Notification of Births Act (1907), or of 48 hours, as in the Tuberculosis Regulations (1912), is given, but a practitioner must notify "on first becoming aware" and a midwife "forthwith." Article VI. contains a phrase that will cause as much trouble as the "exemption section" of the Notification of Births Act (1907)viz., that a midwife must notify "unless the case has been already notified by a medical practitioner." A converse exemption is supplied in Article $V$. $(1 \mathrm{~b})$ for a medical practitioner. The section of the Notification of Births Act referred to has greatly impaired the usefulness of that Act.

As only "certified" midwives are referred to throughout these latest regulations of the Local Government Board, I presume that the oldfashioned midwife, who is only registered and not certified by the Central Midwives Board, need not comply with the regulations.

The medical officer of health is an expositor of preventive and not of curative medicine. Therefore, under these regulations he cannot do more than endeavour to see that an infant notified as suffering from "ophthalmia neonatorum" has prompt treatment at the hands of a private practitioner or in a public institution. If the parent or guardian does not provide this, the medical officer of health can either urge his Council to prosecute the offender under Section 12 of the Children Act, or (that failing) bring the case to the notice of the local representative of the Society for the Prevention of Cruelty to Children.

Feb. 11th, 1914 ,

$$
\text { I am, Sir, yours faithfully, }
$$

\section{A NATIONAL MEDICAL SERVICE. To the Editor of THE LANCET.}

SIR,-There can be no doubt that the articles in THE LANCET, the British Medical Journal, and the Morning Post, to which I alluded in my letter of Feb. 14th, discussed the question of "free choice" solely from the point of view of the im. portance of patients being able to choose their own doctor. Dr. Shaw challenged me to show how such "free choice" could be extended to patients under a State service, but instead of answering my sug. gestions he now shifts the argument to the question of doctors being able to limit their panels by their right of "free choice" of patients. If "free choice" means this right on the part of the doctors and not the right of the patients, then certainly I am " using the words 'free choice of doctor' in some different sense from that generally understood by the profession," but not different from that in which it was used in the articles referred to above, nor from that in which my colleagues in the State Medical Service Association use it.

Dr. Shaw approves of the panel system because doctors are placed in competition to secure patients by pleasing them, and because success in doing so entails increased remuneration. It is just this system of trying to please patients for the sake of personal gain that seems to me and other adrocates of a State Service inadvisable. If this objection were removed by the formation of a whole-time salaried service, no one would be adverse to patients enjoying whatever therapeutic advantages there may be in "free choice of doctor" in so far as that were possible.

Dr. Major Greenwood asks: "Are all the 20,000 panel doctors to be paid uniform salaries, as is usual in a Government service ......?" I cannot think of any Government or municipal service where the 